[Tuck, B. (1995). Generally Fine but Occasionally Overcast with the Possibility of Thunder and Lightning: A Year in the Life of the New Zealand Qualifications Authority. New Zealand Annual Review of Education, 4, 229-245]

\section{Generally Fine but Occasionally Overcast with the Possibility of Thunder and Lightning: A Year in the Life of the New Zealand Qualifications Authority}

\author{
BRYAN TUCK
}

\section{Abstract:}

The New Zealand Qualifications Authority (NZQA) was established by legislation in 1990. It has as a goal the establishment of a single standards setting system (The Framework), which will accommodate all national qualifications in post-compulsory education. There is no distinction made between vocational and academic education.

The discourse of the NZQA is consistent with the characterisation of education as an enterprise, where the "outcomes" are primarily determined by economic objectives, and educational institutions purchase the right to become providers of products. Implementing the Framework, and the core notion of "unit standards" has not been without its problems. Difficulties noted among others include the confusion over the roles and nature of Industrial Training Organisations, the use of participation in the changes as a political lever by secondary teachers, and the opposition of the Association of University Staff. Critics have argued that all of the valued goals of education cannot be expressed in the discourse sanctioned by the NZQA, that the published "unit standards" do not in fact entail descriptions of standards, and that the logic underlying the hierarchy of levels is flawed. Despite the massive changes brought about by the introduction of the Framework, it may well be that these conceptual problems will result in further changes to its character.

卫 he New Zealand Qualifications Authority, established by legislation in 1990, is an independent statutory body, with two central legislated purposes: to establish a Qualifications Framework built on defined standards, and to be responsible for the quality of the provision of programmes associated with the standards on the Framework. The
Framework is to provide a mechanism for the recognition of prior learning and to facilitate transfer between educational qualifications. It has eight levels, and it is the intention that the Framework will accommodate all national qualifications in post compulsory education: trade, technical, professional and higher education. The structure does not differentiate between vocational and academic qualifications and the vision is of a seamless national credit transfer system (NZQA, 1994).

The early emphasis of the NZQA on skills and competence-based assessment parallels movements elsewhere, e.g., Australia, where the Framework of the Australian National Training Authority provided a model for the NZQA's eight level Framework, Scotland and the freestanding units of SCOTVEC, England and the National Council for Vocational Qualification's five level framework. All of these models, unlike that of the NZQA, are firmly embedded in vocational education and training. To paraphrase a popular science fiction series, we are to boldly go where no one has gone before.

The NZQA inherited from a number of defunct agencies a set of qualifications: School Certificate, University Entrance, Bursaries and Scholarship Examinations, Trade Certificates, and a range of credentials from the Authority for Advanced Vocational Awards. These inherited credentials, which are outside the Framework, will eventually be replaced with National Certificates and Diplomas.

Degrees have a special place in the legislation. Approval and accreditation of degrees in universities is the responsibility of the New Zealand Vice Chancellors' Committee (NZVCC), but for all other institutions it is the responsibility of the NZQA. Thus in state-funded polytechnics, such as the Auckland Institute of Technology, the NZQA is responsible for the approval and accreditation of degrees and maintaining standards. Across the road at the University of Auckland, responsibility for accreditation and standards rests with the NZVCC. A bus ride away, staff at the Auckland College of Education will in 1995 be teaching for University of Auckland degrees accredited through the NZVCC with their own degrees accredited through the NZQA.

The response of the NZQA to requests from polytechnics and private training establishments to become degree granting institutions has changed tertiary education. It is instructive to examine the developments at one polytechnic, the Auckland Institute of Technology (AlT), which before the creation of the NZQA had no degree programmes. In a little over two years the NZQA has registered degrees in arts, applied science, business (with five distinctive specialisations), communication studies, 
graphic design, health science (with three distinctive specialisations) and visual arts. In addition the Institute expected to gain registration before 1995 for degrees in health science (midwifery), medical laboratory science, spatial design, business (tourism) and Maori studies. Development is not restricted to undergraduate degrees, and the AlT is waiting for the NZQA to evaluate a master's degree in health science. There are two other polytechnics in Auckland, and together they now offer dozens of degree programmes.

There will be at least seven institutions offering degree programmes on site in the Auckland area during 1995; two will be universities. Careers advisers in Auckland secondary schools report being swamped with literature from competing institutions marketing a kaleidoscope of degrees. Educational guidance has become an increasingly important part of their work. What is happening in Auckland is happening to a lesser degree throughout New Zealand.

The NZQA has outposts in Auckland and Christchurch, and over 140 permanent staff. A number of staff have as their primary function providing the Board of the NZQA with policy advice for government. There have been more than 170 groups developing unit standards, over 2000 unit standards approved, and more than 780 Private Training Establishments registered. The target date of 1997 is given for full implementation of the Framework in one publication, 1998 in another (NZQA, 1994; 1994a). At that stage thousands of unit standards will be registered on the Framework. Initial reaction from some observers is one of surprise at the pace of the change. One polytechnic has written to the NZQA suggesting that too much is happening too quickly, but it is salutary to realise that for other observers the rate of change is too slow (OECD, 1993).

There has been a steady increase in financial support from the Government with a direct grant in 1993-94 for the further development of the Qualifications Framework. It was expected at the time of creation that the NZQA would become self-funding in the tertiary area, and that industry through voluntary levies and staff time would eventually pay most of the costs of the initial needs assessment, development, endorsement and registration of the unit standards and qualifications for its sector. Students as users of a service provided by the NZQA, also pay fees for national examinations. It is difficult for an outsider accurately to estimate the proportion of the NZQA's income sourced from the private sector, but users of its services, in one form or another, must contribute a major portion of its income. The NZQA is the very model of a modern enterprise's enterprise. A significant proportion of its funding comes directly from users. It produces a glossy house magazine of professional quality, Learn, a regular newsletter, $Q A$ News, another newsletter for Maori, Ao Kawe Kupu, and other occasional publications for specific interest groups.

The NZQA is clearly an important arm of government policy as seen by its commitment with the Education Training and Support Agency (ETSA) to the Skill New Zealand Strategy. In one sense the mission of the NZQA is to manage a revolution. Sweeping changes will occur as a result of the implementation of the Framework and the emphasis on unit standards and outcomes. Those who regard the Framework and the associated unit standards as a neutral structure, limited to the creation of a seamless national qualification transfer system, do not understand the nature of the revolution. The NZQA accepts the OECD (1993) conclusion that New Zealand has a "... specific problem hampering skill formation ... the labour force does not possess the generic skills needed to undertake further education and training." The aim of the Qualifications Framework is to create a single comprehensive training system, and, as stated by Barker (1993), it is "industry, or the users of particular skills who should set the standards, that is define the outcomes and the performance criteria. The providers of education and training should not be excluded from the process, but neither should they be the primary participants in it" (writer's emphases).

Teachers and educational institutions are providers. They provide the curriculum and the assessment tasks, and attempt to ensure that the learners, who as users purchase the services of the providers, achieve the standards encoded in a registered set of outcome statements. The goal is "a co-ordinated and interactive system built on a partnership between industry providers and government" (Barker, 1993). A central feature of the goal is the sharp distinction drawn between outcome tasks, curriculum processes and assessment tasks. In one sense, the providers purchase from the NZQA the right to use the registered statements of outcome tasks and the associated imprimatur.

The vision that the NZQA and the Minister of Education have for education is probably best described as a comprehensive seamless system of instrumental education, where the goals are determined primarily by economic imperatives. Users acquire skills and qualifications, which they market to obtain an economic return on their investment. The state requires a return from its investment in education. Thus the latest budget introduces the possibility of the Government purchasing "outputs", 
numbers of graduating students, rather than funding "inputs", Equivalent Full-time Students, in tertiary institutions (AUS Bulletin, 1994).

The language is the discourse of the enterprise culture (Peters, 1992); the good life consists of a steady increase in GDP, low headline inflation, and international competitiveness. Business should be involved in the development and implementation of educational policy. Education will be evaluated in terms of the production of credentials. The desired outcome is a skilled, motivated and flexible employee, and an internationally competitive economy. Human activity is interpreted in terms of economic self-interest. Teachers become "learning managers", students become "inputs" or "outputs" or "purchasers" or "users"; schools, polytechnics and universities become "providers", marketing their "products" and competing for market share. Quality assurance, involving customer evaluations of the relevance and quality of the product, replace notions of excellence embedded in a domain of knowledge. There is little place in the discourse for wonder or surprise at the insight provided by a poetic image.

Fitzsimons and Peters (1994) place the development of agencies such as the NZQA and the ETSA firmly within the politics of human capital and public choice theory. A number of givens underlie these developments: education is a commodity and the resulting knowledge and skills are valued in terms of economic return to the individual; individuals act rationally to maximise economic return; and the golden summer only occurs when individuals and institutions operate in an unfettered market. Thus those of this religious persuasion see us as truly human when we function as independent economic units in a "free market". The rationality of these articles of faith has not gone unquestioned (Fitzsimons and Peters, 1994; Hughes and Lauder, 1991).

It is ironic that while the foundation stone of the NZQA is individualism and libertarianism, legislation and centralised political control are necessary for its implementation and maintenance. Another interesting conundrum is that performance-based assessment is strongly supported by both the "New Right", with its economic agenda, and the "new humanists" such as Taylor (1994), with their concern for the learner. This union of opposites in educational "reform" is of course not new to New Zealand. Snook (1989:16) identified a similar conjunction among the supporters for Tomorrow's Schools. Some saw the proposals as enhancing choice while others saw them as enhancing equity. As Snook noted, "choice is an individualistic value which by and large, operates against equity".
The backgrounds of the members of the Board of the NZQA are consistent with the characterisation of education as an enterprise. The chair is a former principal of Lincoln University College, which has a strong commitment to the applied sciences, two members have senior executive positions in industry, another is a former director of a Regional Employers' Association, another is a former director of a Regional Employment Advisory Committee, another is an organisational development consultant and another is an associate director of a polytechnic. Of the three remaining members, one is a university professor, another a director of a private training establishment and the other is a principal of a secondary school.

In 1992 the Industry Training Act established Industry Training Organisations (ITO). An ITOidentifies the skills required in its industry, creates sets of unit standards and qualifications, which, if acceptable to the NZQA, are registered on the National Qualifications Framework. Each ITO sets up its own training system to meet the needs of its industry. In the old days there were common elements in the training of apprentices across industries. All were indentured, all had night classes and block courses at a polytechnic, and all had the term of the apprenticeship defined by time served. Under the new model, it is possible for an ITO to arrange all of its training at the work site, using a range of providers, and although National Certificates and Diplomas will have some standard requirements, time served will not be one of them. Where no ITO has been established the NZQA has National Standards Bodies (NSB) which fulfil a similar function.

The last two years have seen a fundamental change in vocational education, with the NZQA playing a pivotal role (ETSA and the NZQA 1993, 1994). Education and training in industry will no longer be driven by any universal model of an apprenticeship. Vocational qualifications will be constructed by selecting unit standards from the Framework. The unit standards are modular; so some can be common to qualifications across a number of ITOs, whereas others will be unique to the qualifications of a particular ITO. The changes have been rapid and dramatic, and many employers are confused. A recent survey of 673 companies found that while nearly half "...knew an ITO existed or was being developed in their industry, many could not name the ITO or provided incorrect names such as a polytechnic" (Evening Post, 1994).

In the past, nationwide programmes of training for industry have tended to be located within polytechnics. Full-time or part-time students chose to study for a qualification over a number of years within a single 
polytechnic. In the new model, the ITO can arrange for a number of different providers to teach to the unit standards at different locations, including the work site. The Union of Polytechnic Staff has expressed concern over the development. They suggest that apprentices could become vulnerable to exploitation by employers, when the employer is the assessor for a required unit standard in a qualification (Campus Review, 1994). Certainly 1994 has seen the beginning of a new funding arrangement for polytechnics. In the future they are going to depend more on the funding they receive as providers for ITOs and NSBs and less on the direct funding for Equivalent Full Time Students (New Zealand Herald, 1994a).

The new structure has introduced flexibility and opened up the possibility of competition between providers, an essential element of the enterprise culture. However, irrespective of the discourse of those involved in quality assurance, the ultimate responsibility for the quality of any unit standard or qualification now rests with a single central bureaucracy, the NZQA, and not with any Industry Training Organisation or a National Standards Body. An ITO or NSB develops and "endorses" the unit standard, but it is the NZQA which ultimately determines whether or not a unit or units are "fit for their intended purpose" (NZQA, 1994b).

The managed revolution has been more evolutionary than revolutionary in secondary schools. The NZQA has responsibility for examining School Certificate, Sixth Form Certificate, and Universities Entrance Bursaries and Scholarship. This is a considerable task not without its difficulties, of which the moderation of the internally assessed components of the examinations is worth mentioning. Schools have recently been reminded that "Assessment must be related to the internal objectives of the prescription" and "Content of the assessment activity must be derived from the prescription" (NZQA, 1994c). If this is a problem now, one can only guess at what it will be like when teachers have to generate valid assessment tasks for the numerous unit standards they will have the opportunity to teach to.

As yet the senior secondary curriculum has not been structured around unit standards, standards-based assessment and the Framework. From one perspective the attempts have been frustrated by the Post Primary Teachers' Association (PPTA). From another, the NZQA has frustrated PPTA attempts to "contribute positively to the developments of the new frameworks" (PPTA News, 1994). The PPTA believes that the proposed curriculum reforms and the Qualifications Framework are generally supported by teachers (PPTA News, 1994a). However, the translation of theoretical into practical support is dependent on the Minister of Education accepting the PPTA's invitation to party over the issue of bulk funding. The Minister regards bulk funding as a "vital component for the future of school resourcing" (Evening Post, 1994). Teachers' unions regard bulk funding as a not too subtle attack on conditions of employment, and see the institutionalisation of inequities as an inevitable outcome.

The chair of the recently disbanded Schools Consultative Group regards teacher goodwill as essential for the implementation of "reforms" in secondary education. The final report of the Group, considered by Cabinet in October, ranks the full implementation of the new curriculum and the Qualifications Framework as its first priority (PPTA News, 1994b; New Zealand Herald, 1994b). The Minister still advocates an extension of the Teacher Salaries Grant Scheme Trial. The stage is set for an interesting set of confrontations between the Minister and the PPTA with the NZQA more than just an interested observer.

Secondary teachers will be confronted with changes at a number of levels, e g., curriculum written around outcome statements entailing notions of competency needs to be created, assessment tasks need to become more "authentic" (Wiggins, 1989) and time needs to be created for the additional demands for quality assurance and moderation. The definition of the unit of funding for secondary schools will need to change, and administrators and teachers will need instruction in "enterprise babble". The last budget allocated a considerable sum for the implementation of the Framework, including teacher development. Perhaps the "sweetener" in the Teacher Salary Grant Scheme - the trial schools received inflated incomes for salaries (Dixon and Edwards, 1994) - could also be redirected into teacher education.

On the surface, the major cause of the failure of the seeds of the revolution to germinate in secondary schools is the stony ground of a recalcitrant union. However there have been difficulties in actually creating unit standards in the senior secondary curriculum. It has, for example, taken a considerable period of time to bring forward the draft unit standards in mathematics. Thus attributing responsibility for the lack of progress to a bolshy union is an oversimplification. It is still the case that much of what is valued in education cannot be easily if at all transformed into outcome statements of the type demanded by the NZQA (Elley, 1994). It is probably more than a coincidence that the secondary school exemplars in the NZQA series on Educational Television are Musical Performance and Physical Education. 
Overall 1994 was somewhat of a holding year for the NZQA in secondary schools, but there were some achievements. For example, the PPTA affirmed the phasing out and replacement of School Certificate and Bursary Examinations with National Certificates, and the Principals Lead Group proposed that the Bursary Examination be linked to the Framework. However, even here the endorsed model is a compromise, and the structural changes across the board at the national level have yet to occur. The conservative approach taken by the NZQA is understandable given the linking by the PPTA of the reforms to bulk funding. Perhaps in the coming year the PPTA will change its position; perhaps MMP will change the Minister's position; perhaps schools committed to bulk funding will pilot and promote the changes?

Universities have been relatively isolated from the turmoil as the authority for registering degrees and maintaining standards was devolved to them by legislation. But it should not be assumed that either the Minister or the NZQA is happy with universities being outside the Framework. The General Manager of the Policy and Development Division of the NZQA characterised the Vice-Chancellors as successfully recapturing the university territory for themselves (Barker, 1993). One suspects that the success of the Vice Chancellors' lobby against external quality assurance was a bitter pill to swallow. The establishment of the Ministerial Tertiary Lead Group (MTLG) is probably the reaction. The first term of reference for the MTLG is quite specific:

To resolve issues relating to the inclusion of degrees in the National

Qualifications Framework.

Note, the issue is not whether they should be included but how they are to be included.

The membership of the MTLG is consistent with the assumption that education is an enterprise. A manager within a significant international company is the chair, another member is CEO of the New Zealand Forest Research Institute, and the others are senior administrators in a cross section of tertiary institutions. The foreword and introduction to the Report (Ministerial Tertiary Lead Group, 1994) have international competitiveness and the marketing of New Zealand's international educational services as a major impetus for a Single Harmonised Qualifications Framework.

The third term of reference for the Tertiary Lead Group also clearly places their activity within the parameters of human capital theory and the enterprise culture:
To identify the parameters for standard setting that would enable learners, employers and government to identify the outcomes being purchased.

A degree is thus a commodity, and those purchasing it need to be assured that they are getting value for money.

There has been considerable opposition to the notion that the Framework, with its unit standards and standard-based assessment, is an appropriate model for universities. The Framework of eight levels has the potential to discriminate between levels of achievement within and up to an undergraduate degree, but there is a ceiling effect, and there will be difficulties in discriminating between levels within graduate degrees.

Hall (in press) argues that it is simply not possible to state many of the objectives of university programmes as outcomes of the type proposed by the NZQA. The early emphasis of the unit standards on outcomes, performance and competency is perceived as a major problem for general education (Codd, McAlpine and Poskitt, in press). This is not just a local concern as Bowden and Masters (1992) have raised similar concerns in Australia, and Hyland (1993:57) concludes that the competency approach of the National Vocational Qualifications Authority in England displays "confusion and incoherence in its interpretation and use of the ideas of "knowledge" and "understanding", and so should be resisted by educators committed to these values." A recent critique of the Framework, unusual because it was sponsored by a group one would expect to be ideologically attuned to the NZQA, also raises questions about its appropriateness for general or academic education (Irwin, 1994). Other writers have noted that many of the statements in unit standards are too imprecise to enable valid assessment tasks to be developed by providers (Tuck, in press). Elley (1994) argues strongly that the very title of a "unit standard" is a misnomer as the available unit standards do not entail descriptions of standards.

Those in tertiary education who argue for the relevance of competency-based standards tend to be located in vocational, professional or technological education, for example, Andrew Gonczi at the University of Technology in Sydney. Gonczi (1992) constructs a concept of competence, which assumes that part of being competent is the acquiring, storing and application of knowledge. The NZQA now seems to have a similar position, and the television programme "A Future with Standards" (produced by the NZQA and run on Educational Television on October 26, 1994) has "knowledge and skills", along the horizontal and "levels" up the vertical axis of the Framework. Notable 
for their absence in the unit standards I have examined are statements of affective outcomes, i.e,. attitudes and values.

The Report of the Ministerial Tertiary Lead Group suggests that its members have reflected on these criticisms. A broader and more flexible approach to standards setting than that currently adopted by the NZQA is deemed desirable, educational objectives should address both processes and outcomes, and it is not enough to strive just for competency; excellence is also to be valued. Of critical concern to universities will be the recommendation that a Tertiary Qualifications Co-ordinating Committee be established, independent of but with delegated responsibility from the NZQA, for the registration of all degrees and post-graduate qualifications. The Report makes a distinction between degrees developed by a provider and those developed by National Standards Bodies. The significance of provider degrees is that they are not required to be based on unit standards and evidence for their endorsement is to come from, for example, relevant academic communities. This is an affirmation of the value of education based on academics' understanding of the critical issues in their area, rather than on a particular industrial group's analysis of its current training needs. The authority of both the NZQA and the NZVCC is to some extent compromised, but the Report is adamant that decisions about credit transfer are the prerogative of the providers, not a centralised agency Whether this is enough to satisfy the demands for academic freedom by universities and wananga remains to be seen.

If the ultimate goal of a global economic policy within an unregulated world market is realised through the implementation of the General Agreement on Trades in Services, then universities may have more than just the Framework to worry about. Kelsey (1994) paints a picture in which transnational companies will come to dominate the sector and in which "The ideal of education as the means to convey unique identities and cultural values, as an arena of contest and critique, and as a valued activity irrespective of its market demand, would become a relic of the past" - an inevitable outcome of allowing one type of discourse, that of human capital theory, to control the way we construe culture and education.

The relationship between the NZQA and tertiary staff has some similarity with that between the NZQA and secondary teachers. Representatives of the Association of University Staff (AUS) met the Tertiary Lead Group in July. They had grave reservations over the appropriateness of standards-based assessment and the Qualifications Framework for universities, and warned that "If the Lead Group's advice does not preserve university education then university staff cannot be counted on to co-operate" (AUS Bulletin, 1994a). Thus both tertiary and secondary teachers' unions have threatened to work against the introduction of the Framework. The difference is that the AUS, unlike the PPTA, have reservations over its pedagogical merit (Codd, 1994).

Where did all of this leave the NZQA at the end of 1994? The Framework and the associated discourse have been accepted by institutions which have their antecedents in vocational education and training. They have grasped the opportunity provided by the NZQA to become degree granting institutions. As a consequence, a two-tiered degree granting system has developed, with fundamental research having a low priority in one tier. The Report of the Ministerial Tertiary Lead Group has yet to be worked through. It has recommended that all degrees be registered on the Framework by a committee not responsible to the NZVCC, but it also clearly leaves the gate open for universities and other tertiary institutions to develop degrees outside the narrow constraints of unit standards.

Progress in industrial education and training was rapid during 1994. The NZQA developed a close working relationship with the ETSA. There were been rumours of some ITOs and NSBs having difficulty in drawing up unit standards acceptable to the NZQA, and even of one advisory group being dismissed. The NZQA must be concerned over the misunderstandings which exist within industry over the role and function of ITOs. These need to be settled, because ITOs have a key role in industrial training. The Ministerial Tertiary Lead Group (p. 7) also recommended that a "review of the proliferation of industry training organisations be undertaken"; so there is reasonably widespread concern. Perhaps the NZQA and the ETSA would be advised to heed the reservations of Wilson and Englehard (1994) over the ability of off-thejob providers to support the workplace focus of the Australian developments in "trade training".

The year was an interesting one for the NZQA and the PPTA. The Minister's single-minded advocacy of bulk funding makes it difficult for the NZQA to implement the Framework within senior secondary schools. Secondary schools have yet to feel the impact of the changes on teaching and learning, and the national examinations. There may be resistance to some of the changes from the public when the implications are appreciated.

Although gaining a significant proportion of its budget from the private sector, the NZQA will require substantial Government funding 
in the short to medium term. Once the Framework is fully implemented, with thousands of unit standards being continually updated and validated and extensive systems of moderation and quality assurance having to be sustained, the community will bear the considerable cost of the vision. At that stage there could be only one sanctioned discourse: that of the enterprise culture and the human capital theorist.

Overall, the train which is the New Zealand Qualifications Authority has steamed on, with, at times, the tracks being laid just ahead of the train. In one sense it is a good example of the design and build philosophy, with unit standards being assigned to levels concurrently with the NZQA preparing "draft policy proposals" and "further draft policy proposals" on level descriptors (Methven, 1994, 1994a). There are conceptual problems with the assumptions underlying the concept of a unit standard and the hierarchical Framework. The eight level model adopted from Australia is based on a hierarchy of occupations. The level descriptors produced under contract by the New Zealand Council for Educational Research are similar. It is problematic that the acquisition of skills, values, attitudes and knowledge in curriculum areas such as science, literature, language and mathematics can be similarly sequenced (Elley, in press).

The adequacy of the existing descriptors of levels is also open to question. Peddie (1993) suggests that in some cases it is probably necessary to use additional criteria, outside of those published, for the placement of unit standards. Qualification frameworks based on notions of hierarchies of generic skills or key competencies also make assumptions which are seriously critiqued by a number of writers (Barrow, 1991; Wolf, 1991). The essential essence of the Framework has remained constant, eight hierarchical levels with standards-based assessment, but its brief history suggests that its operational definitions are not laid in stone. I suspect further revisions of the defining characteristics of the Framework are inevitable if it is to survive.

A study of the robustness of the Framework in practice will be viable in the next few years. By then the definitions of the eight levels should have been established operationally and the ambiguities surrounding the notion of a standard clarified. The place of notions of excellence and merit (Peddie, 1994) in the scheme will hopefully have been settled. The NZQA has made a public commitment to a seamless transferable qualification system with a Framework of objective levels, and unlike its counterparts overseas makes no distinction between vocational and general/academic education. Presumably it will be able in the future to provide a plausible answer to a question such as the following: are the graduates of a course on Te Ao Tawhito, taught by a wananga at Temuka, to a unit standard registered at Level 3 on the Framework, of an equivalent standard to graduates from a unit standard on Viticultural Management, also registered at Level 3, but taught by a Gisborne viticulturalist and vintner? It will be interesting to see how satisfying the answer and its justification will be to the various stakeholders in education.

\section{References}

AUS Bulletin. "Purchasing Outputs in Tertiary Education," August 20, 1994:9.

AUS Bulletin. "University Degrees and the Framework," August 20, 1994a:3.

Barker, A. “The New Zealand Qualifications Framework: practical issues in implementation," Paper presented at the Tertiary Education Conference, Wellington: 1993.

Barrow, R. "The Generic Fallacy", in Educational Philosophy and Theory, 23:1, 1991:7-17.

Campus Review. "Competitive Funding Muzzles Criticism," October 6-12, 1994:13.

Bowden, J. and Masters, G. Implications for Higher Education of a Competency-Based Approach to Education and Training: Interim Report, Melbourne: RMIT \& ACER, 1992.

Codd, J., McAlpine, D. and Poskitt, J. “Assessment Procedures in New Zealand: Educational Reform or Political Agenda", in Setting the Standard: Issues in the Assessment of Competence in National Qualifications, R. Peddie and B. Tuck (eds), Palmerston North: Dunmore (in press).

Codd, J. "A Framework for University Qualifications," AUS Bulletin, 21, 1994:6-7.

Dixon, K. and Edwards, W. The Financial Picture Emerging From Schools in the Salaries Grant Scheme Trial: A Preliminary Study Based on the First Year, Palmerston North: ERDC, Massey University, 1994.

Elley, W. "Fundamental Flaw at the Heart of the New Qualifications Plan", in The Christchurch Press, November 17, 1994:11.

Elley, W. "What is Wrong with Standards-based Assessment?" in Setting the Standard: Issues in the Assessment of Competence in National Qualifications, R. Peddie and B. Tuck (eds), Palmerston North: Dunmore (in press). 
ETSA and the NZQA. Taking the Step to Skill New Zealand, Wellington: ETSA and the NZQA, 1993.

ETSA and the NZQA. A New Strategy for Lifelong Education and Training, Wellington: ETSA and the NZQA, 1994.

Evening Post. "Smith Loses Out on Funding Proposal," October 10, 1994:3.

Evening Post. "Employers Spend More on Training," October 13, 1994a:21.

Fitzsimons, and Peters, M. "Human Capital Theory and the Industry Training Strategy in New Zealand", in Journal of Educational Policy, 9:3, 1994:245-266.

Gonczi, A. "An Integrated Approach to Professional Education and Assessment: a Consideration of Arguments For and Against," Unpublished paper, Sydney: University of Technology, 1992.

Hall, C. "Integration of University Qualifications into the National Qualifications Framework: Obstacles and a Way Forward," in Setting the Standard: Issues in the Assessment of Competence in National Qualifications. R. Peddie and B. Tuck (eds), Palmerston North: Dunmore (in press).

Hughes, D. and Lauder, H. "Human Capital Theory and the Wastage of Talent in New Zealand", in New Zealand Journal of Educational Studies, 26:1, 1991:5-20.

Hyland, T. "Competence, Knowledge and Education", in Journal of Philosophy and Education, 27:1, 1993:57-68.

Irwin, M. Curriculum, Assessment and Qualifications: An Evaluation of Current Reforms, Auckland: Education Forum, 1994.

Kelsey, J. "Gatt and Tertiary Education", AUS Bulletin, 1994:18.

Methven, P. Level Descriptors. Draft Policy Proposal, Wellington: New Zealand Qualifications Authority, 1994.

Methven, P. Level Descriptors. Further Draft Policy Proposal, Wellington: New Zealand Qualifications Authority, 1994a.

Ministerial Tertiary Lead Group. “A Single Harmonised Qualifications Framework," Report of the Ministerial Tertiary Lead Group, Wellington: Ministry of Education, 1994.

New Zealand Herald. "Polytechnic Funding Shift," November 21, 1994a, Section 1:1.

New Zealand Herald. "Bulk Funding Given Back Seat," October 13, 1994b, Section 1:3.
NZQA. "The Assessment and Recognition of Skills and Competencies in New Zealand," A paper for the OECD Education Committee and the Employment, Labour and Social Affairs Committee, Wellington: NZQA, 1994.

NZQA. QA News, 23, 1994a:3.

NZQA. "Key Components of the National Qualifications Framework. Framework for Industry," Wellington: NZQA, 1994b.

NZQA. "Evaluation of Internally Assessed Components of Universities Entrance, Bursaries and Scholarship Subjects. ACES Update," Wellington: NZQA, 1994c.

OECD. Economic Surveys 1992-93: New Zealand, Paris: OECD, 1993.

Peddie, R. "Standards, Levels, Grades and 'Merit', A Critical Analysis," Paper presented at National Assessment Research Forum, conducted by CBT Working Party of VEETAC, Sydney: 1993.

Peddie, R. "Difficulty, Excellence and Levels: Implications for a Qualifications Framework," A discussion paper for the New Zealand Qualifications Authority, 1994.

PPTA News. "President Reviews Progress," 15:9, 1994:2.

PPTA News. "Modernisation or Confrontation: Government to Decide," 15:10, 1994a:2.

PPTA News. "SCG Wraps Up," 15:10, 1994b:4.

Peters, M. "Starship Education: Enterprise Culture in New Zealand", in Access, 11:1, 1992:1-12.

Snook, I. "Educational Reforms in New Zealand: What is Going on?" Access, 8:2, 1989:9-18.

Taylor, C. "Assessment for Measurement of Standards: the Peril and Promise of Large Scale Assessment Reform", in American Educational Research Journal, 31:2, 1994:231-262.

Tuck, B. "Issues of Objectivity in Assessment: a Plea for Moderation," in Setting the Standard: Issues in the Assessment of Competence in National Qualifications, R. Peddie and B. Tuck (eds), Palmerston North: Dunmore (in press).

Wiggins, G. "A True Test: Toward More Authentic and Equitable Assessment", in Delta Kappan, 70:9, 1989:703-13.

Wilson, B. and Englehard, M. "Changes to Trade Training", in Australian Journal of Career Development, 3:1, 1994:22-28.

Wolf, A. "Assessing Core Skills: Wisdom or Wild Goose Chase?" in Cambridge Journal of Education, 21:2, 1991:189-201. 


\section{Acknowledgement}

The writer wishes to acknowledge comments by David Lythe, Dennis McGrath, Roger Peddie and Michael Peters on an earlier draft of this chapter.

\section{The author}

Bryan Tuck, Senior Lecturer, Education Department, University of Auckland has been writing and undertaking research in the area of assessment and evaluation since the early 1970s. Recent publications include joint editorship of a book of readings on standards-based assessment, a study of selected groups of students enrolled in Reading Recovery, reliability of essay marking and adolescents' attitudes towards gender roles within work. 